\title{
Developing Mental Toughness with Mental Training and Meditation
}

\author{
Rıdvan Ekmekçi and Bülent Okan Miçooğulları
}

\begin{abstract}
Mental toughness is one of the most important characteristic of sport. Athletes must have optimal mental toughness especially individual sport like swimming. Mental training and meditation are using to develop athletes' mental abilities in sport psychology. Therefore we focused on improving mental toughness level with mental training and meditation. Purpose of the study was improving mental toughness score of the swimmers with mental training and meditation. Pre-test and post-test was applied before and after to the swimmers according to 12 weeks mental training and meditation program. Participants were 6 national swimmers age 15 to 17. Pre-test mental toughness score was avg: 3.2 , (total 38.12) posttest score was 4.1 (total 45.37). Also confidence, consistency and control score of the swimmers were improved. Problem solving score was 96,25 (higher score is weak problem solving ability) in pre-test. Post-test score of the problem solving was 78,25. It is approximately $16 \%$ of improvement after 12 weeks mental training and meditation. Swimmers performance was $18 \%$ of better at the competitions in 2019 than previous year, when we compare that. As a result, mental training and meditation improving swimmers mental toughness score. Therefore swimmers performing better at training and at the competition.
\end{abstract}

Keywords - Mental toughness, Mental training, Meditation, Sport psychology, Swimming.

\section{INTRODUCTION}

Athletes, coaches, and applied sports psychologists have consistently referred to mental toughness as one of the most important psychological characteristics related to outcomes and success in elite sport, although researchers have, until recently, devoted little time to studying this concept (Crust, 2007).

Mental abilities which human need to use it for performance like confidence, concentration, focusing, attention, stay calm and in control. To use these mental abilities they need to train their brain. Mental training helps people especially athletes to improve their mental abilities. Mental toughness is a research topic which is one of the most important factors that to use mental abilities efficiently. Therefore athletes need to improve their mental toughness level to cope with stress and focus on performance. Athletes and players are hard worker of the sport field. They get tired mentally and physically after training and

Rıdvan Ekmekçi, Department of Sport management, Faculty of Sport Sciences, Pamukkale University, Turkey.

Bülent Okan Miçooğulları, Dept. of PE. \& Sports, Faculty of Education, Nevşehir Hacı Bektaş Veli University, Turkey. competition. Average athlete is working at least 3-4 hours a day to reach higher level performance. They do some mental training like concentration exercise, meditation, imagery and mindfulness while there are practicing physically.

Especially swimmers are facing stress and anxiety during training and competition. Level of stress their having effecting swimmers mental toughness level. Indeed, athletes themselves, coaches, members of the press and sports commentators have cited mental toughness as core to the execution of successful performance, while certain psychologists working in the field of sport suggest mental toughness as key to the advancement of knowledge regarding successful athletes (e.g. Bull et al., 1996; Goldberg, 1998; Gould et al., 2002; Loehr, 1982, 1986, 1995). Since the 1950s, mental toughness has been associated with winning performances and linked to the characteristics of sporting champions (Mallalieu and Hanton, 2010)..

The field of sports psychology increased considerably among athletic competitions and disciplines. Before the appearance of scientific attempts, athletes had to manage the psychological skills by themselves. The role of coaches, managers, and other staff was crucial in order to help athletes improve (Stonkus, 2011). However, trainers and sport psychologists around the world believe that future records will be broken mainly due to the increased attention given to the psychological parameters of athletes (Ekmekci and Micoogullari, 2018). Therefore mental training is an important process of elite performance.

Developing mental toughness is a process of mental training. Some of the most important psychological skills are relaxation, imagery, concentration, confidence, problemsolving skill, focus, anxiety, and emotional control (Ekmekci and Micoogullari, 2018). Athletes are need to work on these skills to improve their mental toughness level. Most important exercises are meditation, breathe focusing techniques, mindfulness and imagery for improving mental toughness.

Many researches have shown that mental training using motor imagery, like physical practice, can produce changes in brain structure and function that are associated with improved subsequent performance of a motor skill (Guillot and Collet, 2005; Munzert et al., 2009, Ekmekci 2017, 2018, Ekmekci and Micoogullari, 2018). In some studies, mental training (Wohldmann et al., 2008), as well as combined mental and motor practice (Olsson et al., 2008) has been associated with greater transfer of learning than physical practice, that is, better performance on novel tasks that call upon the trained 
skill. These data support the idea that mental training using motor imagery may strengthen more abstract representations that do not involve specific effectors, thereby fostering process-specific learning that more easily generalizes across stimuli and tasks. Initial evidence for this idea comes from an fMRI study by Olsson et al. (2008), who showed facilitated transfer of learning after combined motor and mental training that was related to changes in the connections from both motor and cognitive systems to the cerebellum. Also statistical results of the athletes performance shows us mental training and meditation help to improve their efficiency. On the other hand, I have many examples and explanation by the athletes, how they are feeling after mental training and meditation as a psychological consultant. Especially meditation after practice and training can reduce physical symptoms of being exhausted and inner balance disorder of nervous system. It is important to have always in balance physically and mentally to have better performance.

To conclude, mental training of motor skills leads to changes in brain circuitry and behavior, just as physical training produces changes in brain circuitry and behavior. Yet, the mechanisms underlying mental and physical training of motor skills are not identical. Notably, mental training may improve motor performance by strengthening more abstract representations, and thereby promote transfer of learning to novel task contexts (Slagter et all, 2011). Meditation can reduce stress level and athletes performance can be improve.

\section{METHOD}

\begin{tabular}{|c|c|c|c|c|c|c|}
\hline & \multicolumn{2}{|c|}{ Paired Differences } & & \multirow[b]{2}{*}{$\mathrm{t}$} & \multirow[b]{2}{*}{ Df } & \multirow[b]{2}{*}{ Sig. } \\
\hline & Mean & Std. Dev. & & & & \\
\hline Pre Confidence - Post Confidence & -.77 & .37 & -5.87 & & 6 & 00 \\
\hline Pre Constancy - Post Constancy & -.34 & .20 & -4.88 & & 6 & 00 \\
\hline Pre Control - Post Control & -.42 & .41 & -5.72 & & 6 & 00 \\
\hline Pre Tot. MT - Post Tot. MT & -1.45 & 1.01 & -5.71 & & 6 & 00 \\
\hline Pre PSI - Post PSI & -5.09 & 1.81 & -6.56 & & 6 & 00 \\
\hline
\end{tabular}

Problem solving inventory (PSI) and mental toughness inventory (MTI) was used to examine players' cognitive skills. Before and after tests was applied to the referees to understand 12 weeks practise effect on problem solving and mental toughness situation. Paired Sample T-test was used to analyze data of PSI and MTI.

The aim of this study was to examine the impact of 12 weeks period of concentration, imagery and mindfulness meditation training session on problem solving and mental toughness score which includes 3 sub-factors confidence, control and constancy. Also EEG devices and Inner balance sensor was used to understand swimmers stress level and inner balance score before, during and after trainings. 12 weeks mental training and meditation protocol was applied to the swimmers.

\section{FINDINGS AND DISCUSSION}

Participants were 6 national swimmers age 14 to 17 . Pre-test mental toughness score was average; 3.2 , post-test score was 4.1. Mental toughness pre-test total score was 38.12. After 12 weeks mental training total mental toughness total score rise up to 45.37. Mental toughness score improved 15\%. Problem solving score was 96,25 (higher score is weak problem solving ability) in pre-test. Post-test score of the problem solving was 78,25 . It is approximately $16 \%$ of improvement after 12 weeks mental training and meditation. You can see on the tables there are significant differences between pre-test and post-test scores.

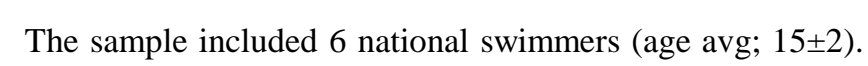


TABLE II: DESCRIPTIVE STATISTIC

\begin{tabular}{|l|l|l|}
\hline Descriptive Statistics & Mean \\
\hline Pre-Confidence Level & N & 08.52 \\
\hline Pre-Constancy Level & 6 & 10.20 \\
\hline Pre-Control Level & 6 & 09.35 \\
\hline Post-Confidence Level & 6 & 15.78 \\
\hline Post-Constancy Level & 6 & 14.45 \\
\hline Post-Control Level & 6 & 13.10 \\
\hline Pre-Total MT & 6 & 38.12 \\
\hline Pre-Total PSI & 6 & 96.25 \\
\hline Post-Total MT & 6 & 45.37 \\
\hline Post-Total PSI & 6 & 78.25 \\
\hline
\end{tabular}

There were significant differences between pre-test and post-test score of problem solving skill and mental toughness inventory. Confidence, control and constancy level of players are improved after 12 weeks period concentration, imagery and mindfulness meditation training session. Mental training is very important to improve focusing, confidence, problem solving abilities, maintain concentration and stay calm. Like many researches (Gould and Eklund 1992, Grush 2004, Ekmekci and Micoogullari 2018) shown that mental training is very important to improve cognitive skills, our study shown that mental toughness and problem solving can be improved by meditation and mental training. These two features are important for the sportive performance. It is well known that meditation is important to cope with stress and anxiety. Also swimmers concentration level is effective on their performance which improves by mental training.

\section{REFERENCES}

[1] Crust L., (2007) Mental toughness in sport: A review, International Journal of Sport and Exercise Psychology, Vol5-3, https://doi.org/10.1080/1612197X.2007.9671836

[2] Ekmekci R., (2017) Sporda Zihinsel Antrenman, Detay Yayıncılik, Ankara

[3] Ekmekci R., (2018) Hakemlikte Zihinsel Hazırlık, Detay Yayıncılık, Ankara

[4] Ekmekci R., Micoogullari B. O., (2018). "Examination and Comparison of Psychological Characteristic of American Football Players and Handball Players". Universal Journal of Educational Research 6(11): 2420-2425, $2018 \quad$ http://www.hrpub.org DOI: 10.13189/ujer.2018.061104

[5] Gould D., Eklund R.C., Jackson S.A., (1992) "U.S. Olympic wrestling excellence: I. Mental preparation, precompetitive cognition, and affect". The Sport Psychology; 6, 358-382 https://doi.org/10.1123/tsp.6.4.358

[6] Guillot, A., and Collet, C. (2005). Contribution from neurophysiological and psychological methods to the study of motor imagery. Brain Res. Rev. 50, 387-397. ttps://doi.org/10.1016/j.brainresrev.2005.09.004

[7] Grush, R. (2004). The emulation theory of representation: motor control, imagery, and perception. Behav. Brain Sci. 27, 377-396. https://doi.org/10.1017/S0140525X04000093
[8] Jeannerod, M. (1994). The representing brain - neural correlates of motor intention and imagery. Behav. Brain Sci. 17, 187-202. https://doi.org/10.1017/S0140525X00034026

[9] Lacourse, M. G., Orr, E. L. R., Cramer, S. C., and Cohen, M. J. (2005). Brain activation during execution and motor imagery of novel and skilled sequential hand movements. Neuroimage 27, 505-519. https://doi.org/10.1016/j.neuroimage.2005.04.025

[10] Mallalieu S, Hanton S, (2010) Advance Applied Sport Psychology; A Review, Routledge

[11] Munzert, J., Lorey, B., and Zentgraf, K. (2009). Cognitive motor processes: the role of motor imagery in the study of motor representations. Brain Res. Rev. 60, 306-326 https://doi.org/10.1016/j.brainresrev.2008.12.024

[12] Nyberg, L., Eriksson, J., Larsson, A., and Marklund, P. (2006). Learning by doing versus learning by thinking: an fMRI study of motor, and mental training. Neuropsychologia 44, 711-717. https://doi.org/10.1016/j.neuropsychologia.2005.08.006

[13] Olsson, C. J., Jonsson, B., and Nyberg, L. (2008). Learning by doing and learning by thinking: an fMRI study of combining motor and mental training. Front. Hum. Neurosci. 2:5. doi: 10.3389/neuro.09.005.2008

[14] Slagter H. A. , Davidson R. J. and Lutz A. (2011) Mental training as a tool in the neuroscientific study of brain and cognitive plasticity." https://doi.org/10.3389/fnhum.2011.00017

[15] Weinberg R., Richardson P., (1996) Psychology of Officiating, Human Kinetix , USA 